\title{
Primary bone tumours in Kashmir valley a retrospective histopathological study
}

\author{
Lateef Ahmad Wani ${ }^{1 *}$; Farzana Bashir Ashai ${ }^{2}$; Bilal Musharaf Banday ${ }^{2}$; \\ Aadil Ashraf ${ }^{2}$; Shaista Mushtaq ${ }^{2}$; Mohd. Saleem Itoo ${ }^{3}$; Ruby Reshi ${ }^{4}$ \\ ${ }^{I}$ Assistant Professor, postgraduate Department of Pathology, Government Medical College, Srinagar, J\&K, India \\ ${ }^{2}$ Senior Resident, postgraduate Department of Pathology /Forensic Medicine, Government Medical College, Srinagar, J\&K, India \\ ${ }^{3}$ Associate Professor, postgraduate Department of Anatomy, Government medical College, Srinagar, J\&K, \\ ${ }^{4}$ Professor and Head, postgraduate Department of Pathology, Government Medical College, Srinagar, J\&K, India \\ *Corresponding author E-mail: drlateefwani@gmail.com
}

Copyright () 2014 Lateef Ahmad Wani et al. This is an open access article distributed under the Creative Commons Attribution License, which permits unrestricted use, distribution, and reproduction in any medium, provided the original work is properly cited.

\begin{abstract}
The present study was carried out in the postgraduate department of Pathology at Government Medical College, Srinagar, India, to study the histopathological pattern of primary bone tumors in Kashmir valley over a period of 15 years. During this study, 373 histologically proven primary bone tumors were analyzed. Out of these, 298 were benign $(79.89 \%)$ and 75 were malignant $(20.10 \%)$. Peak incidence was in the second and third decade of life with male predominance. Among the malignant tumors, the highest incidence was that of Osteosarcoma (52\%), followed by Ewing's sarcoma (24\%) and Chondrosarcoma (14\%). Osteochondroma (49\%) was the most frequent tumor in the benign category. The most commonly affected bones were femur, tibia and humerus in that order. Comparison with similar studies from other parts of the globe indicate that the relative frequency of primary bone tumors appears to be low but shows a rising trend in the last 10 years in this part of the world.
\end{abstract}

Keywords: Benign Bone Tumours; Chondrosarcoma; Hematoxyli; Immunohistochemistry; Osteosarcoma, Soft Tissue Sarcoma.

\section{Introduction}

Bone tumors are diverse in their clinical and morphological features and range in behavior from innocuous to rapidly fatal. Accurate diagnosis, proper staging and appropriate treatment are thus necessary to ensure maximum patient survival and maintain optimal function of the affected body parts.

Primary bone tumors are relatively uncommon lesions constituting less than $1 \%$ of all cancers worldwide [1], [2], [3]. Some of these primary bone tumors display marked intra and international variations in incidence, size and age distribution [3-12]. This may be a reflection of unrepresentative selection of cases, diagnosis and definitions applied, nature of hospital practice, availability of adequate facilities, man power and lack of coordination between surgeon, radiologist and pathologist.

The precise incidence of specific bone tumours is not known as many lesions are not biopsied, however, benign outnumber malignant counterparts. This has resulted in lack of meaningful data concerning relative frequency and incidence of various types of bone tumours.

In Africans, bone tumours account for $1 \%$ of malignant tumours [6]. Bone cancers represent $0.9 \%$ of total number of incident cancers seen in greater Bombay with higher incidence in males [1]. Frequency of bone tumours in eastern Libya was seen to be low [9]. Bone tumours comprise about $5 \%$ of childhood neoplasms with osteosarcoma being the most common type [13]. In the US about 2100 new case of bone cancers are diagnosed annually and cause approximately 1300 deaths [14]. Coley has estimated that the incidence of osteosarcoma is one per 100000 persons in the US [10]. In their survey of malignant disease in Africans, Higginson and Oettle (1960) found that bone tumours were less frequent in Africans than among the US population. They represented $0.85 \%$ of 3172 cases of malignant tumours [15]. 
Bone tumours have a remarkably consistent predeliction for certain skeletal sites and even for precise localisation in specific bones, thus, anatomic localization can provide important clues to diagnosis. For example, osteosarcoma mostly occurs around knee joint [15] and proximal end of humerus is the most common location for chondroblastoma [16]. Osteomas are predominantly found in paranasal sinuses, while as enchondromas have short tubular bones of hands and feet as their favourite site [14]. Giant cell tumours commonly arise in epiphysis. Nonepiphyseal giant cell tumours also occur but are very rare and occur mostly in younger patients [17]. Ewing's sarcoma and Adamantinoma commonly arise in diaphysis. The site of predilection for osteosarcoma and giant cell tumours are at the ends of long bones where there is disc of maximal growth and the growth period is longest.

Bone tumour incidence and mortality is higher in males than in females at all age groups, with a peak ranging from 15 20 years, then a low level in young adult life and a steady increase after 40 years of age [5].

Although as a group, bone tumours affect all ages and can arise in virtually every bone, specific types of bone tumours target certain age groups and anatomic sites. Benign tumours have their greatest frequency within the first three decades of life, whereas in elderly, a bone tumour is likely to be malignant. For instance, most osteosarcomas occur during adolescence and about half arise around knee. In contrast, chondrosarcomas tend to develop in mid to late adult life and involve trunk, limb girdles and proximal long bones. Malignant fibrous histiocytoma (including fibrosarcoma) and chordoma occur but rarely and show a gradual increase in incidence with age and occur most frequently in patients older than 50 years of age [3].

Some tumours are more prevalent in certain geographic areas, such as giant cell tumours occur more frequently in Chinese people than in those residing in western countries (approximately 20\% of all primary bone tumours) [18] and osteosarcoma has lower incidence in some Asian and Latin American populations [13].

Some races are affected more by certain types of tumours, such as blacks ( $<15$ years) are affected more than whites by osteosarcoma while as reverse is true for Ewing's sarcoma and chondrosarcoma [4].

Some pre-existing conditions of the bone are associated with the development of bone tumours, like paget's disease has long been linked to many of the osteosarcomas developing in later decades of life (> 60 years). Malignant fibrous histiocytoma occurs secondary to paget's disease, radiation damage, bone infarction and chronic osteomyelitis [19].

\section{Materials and methods}

The present study was conducted in the post graduate department of pathology, government medical college, Srinagar, Kashmir, India. All bone tumors diagnosed from January 1994 to December 2008 were analyzed from the departmental records for age, sex, site and pathological findings. The study was restricted to primary bone tumors. The neoplasms of marrow origin and metastatic tumors were excluded in this study. In addition to routine hematoxylin and eosin stains, special stains and immunohistochemistry were used in relevant cases.

\section{Results}

During this study period, 373 patients (215 males and 158 females) had histologically proven primary bone tumors. 298 patients $(79.89 \%)$ had benign bone tumors (171 males, 127 females) whereas 75 patients $(20.11 \%)$ had malignant bone tumors (44 males and 31 females) comprising $0.98 \%$ of total malignancies (7619) diagnosed during this study period as shown in Figure [1].

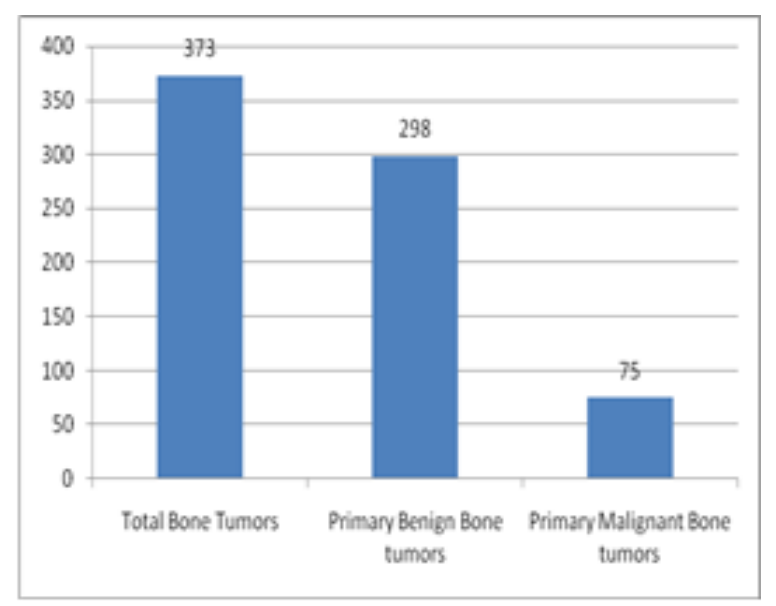

Fig. 1: Distribution of Primary Bone Tumors.

Males (54.95\%) were affected more than females (45.04\%) with a male female ratio of 1.3:1, as shown in figure [2], [3], and [5]. Most patients with primary bone tumors (both benign and malignant) irrespective of sex were seen in the second decade of life, followed by third decade, as shown in figure [4], [6]. 


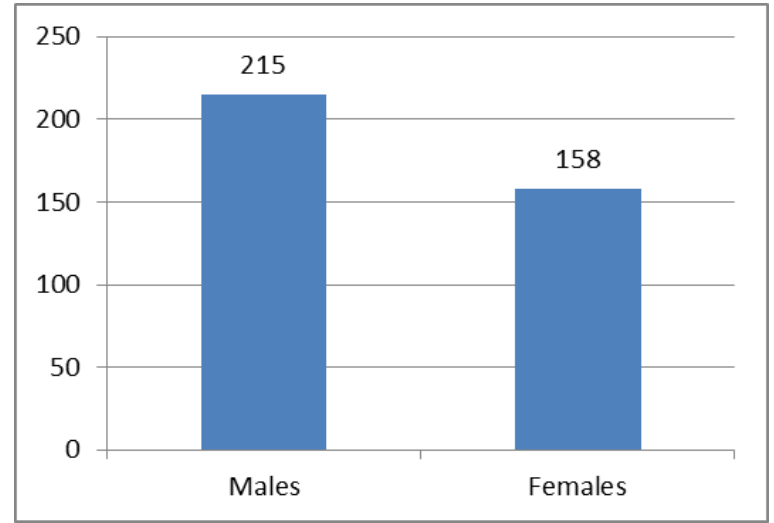

Fig.2: Sex Distribution of Primary Bone Tumors.

Table 1: The Common Primary Benign Bone Tumors Seen In Decreasing Order of Frequency Were As Follows

\begin{tabular}{llllllll}
\hline S. & Benign Tumors & Total & $\begin{array}{l}\text { Percentage } \\
(\%)\end{array}$ & Males & Females & M:F & $\begin{array}{l}\text { Commonest Age Group } \\
\text { Affected in years }\end{array}$ \\
\hline No & Osteochondroma & 146 & 48.99 & 88 & 58 & $1.5: 1$ & $10-19$ \\
2. & Chondroma & 77 & 25.83 & 44 & 33 & $1.3: 1$ & $10-19$ \\
3. & Giant Cell Tumor & 43 & 14.42 & 19 & 24 & $1: 1.2$ & $20-29$ \\
4. & Osteoid osteoma & 21 & 7.04 & 13 & 8 & $1.6: 1$ & $10-19$ \\
5. & Chondromyxoid Fibroma & 6 & 2.01 & 4 & 2 & $2: 1$ & $10-30$ \\
6. & Osteoma & 3 & 1 & 1 & 2 & $1: 2$ & $40-49$ \\
7. & Benign Fibrous & 2 & 0.67 & 2 & 0 & $2: 0$ & $20-29$ \\
\hline
\end{tabular}

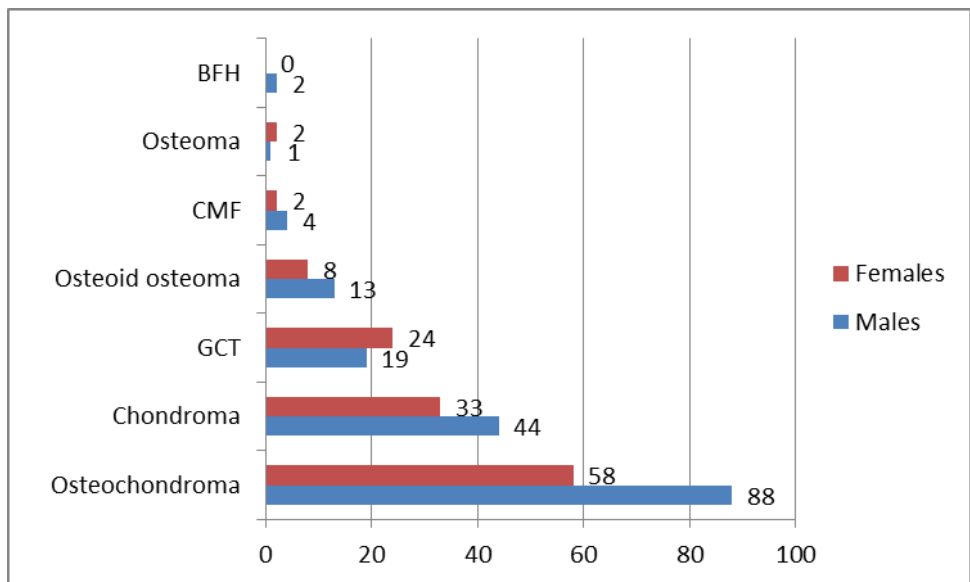

Fig.3: Sex Distribution of Primary Benign Bone Tumors

$\mathrm{CMF}=$ Chondromyxoid fibroma; GCT=Giant cell tumor; BFH=Benign Fibrous Histiocytoma

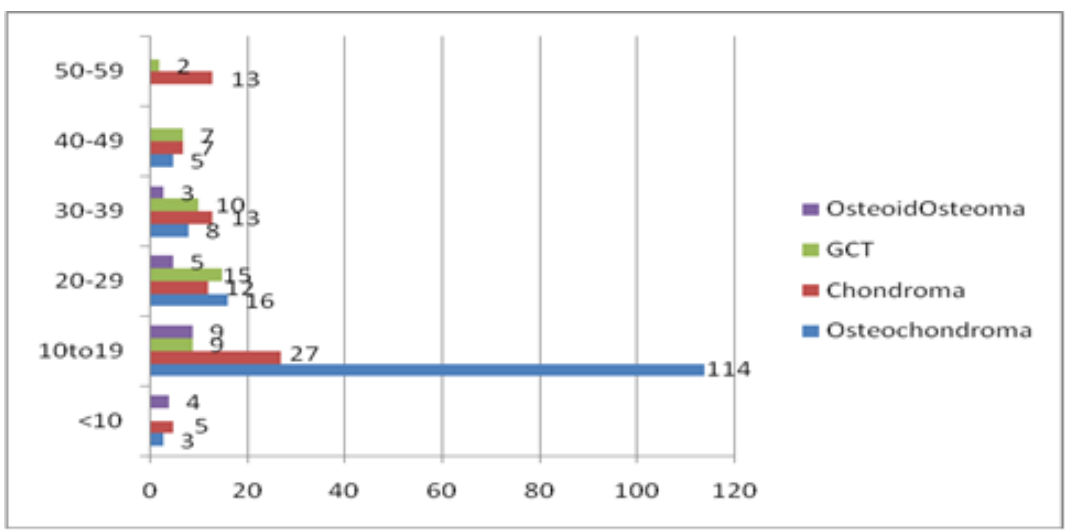

Fig. 4: Age Distribution of Primary Benign Bone Tumors. 
Table 2: For Primary Malignant Bone Tumors, The Frequency Was As Follows:

\begin{tabular}{llllllll}
\hline S.No. & Malignant Tumors & Total & $\begin{array}{l}\text { Percentage } \\
(\%)\end{array}$ & Males & Females & M:F & $\begin{array}{l}\text { Commonest Age Group } \\
\text { Affected in years }\end{array}$ \\
\hline 1. & Osteosarcoma & 39 & 52 & 22 & 17 & $1.2: 1$ & $10-19$ \\
2. & Ewings Sarcoma & 18 & 24 & 12 & 6 & $2: 1$ & $10-19$ \\
3. & Chondrosarcoma & 11 & 14.6 & 6 & 5 & $1.2: 1$ & $30-39$ \\
4. & $\begin{array}{l}\text { Soft Tissue Sarcoma } \\
\text { (Not otherwise specified) }\end{array}$ & 5 & 6.6 & 3 & 2 & $1.5: 1$ & $50-59$ \\
5. & Malignant Fibrous & 2 & 2.6 & 1 & 1 & $1: 1$ & 35 \& 32 years \\
\hline
\end{tabular}

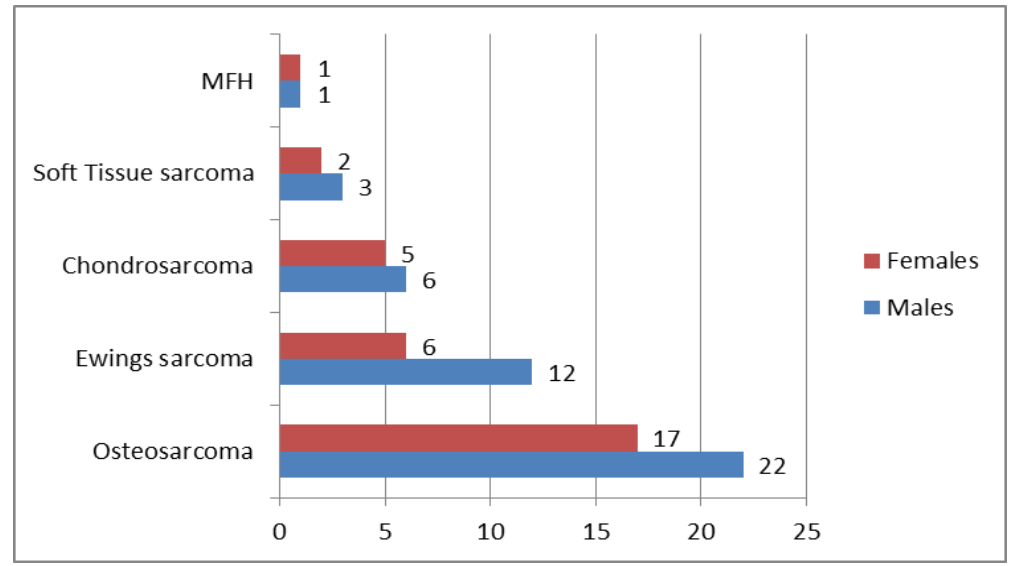

Fig. 5: Sex Distribution of Primary Malignant Bone Tumors.

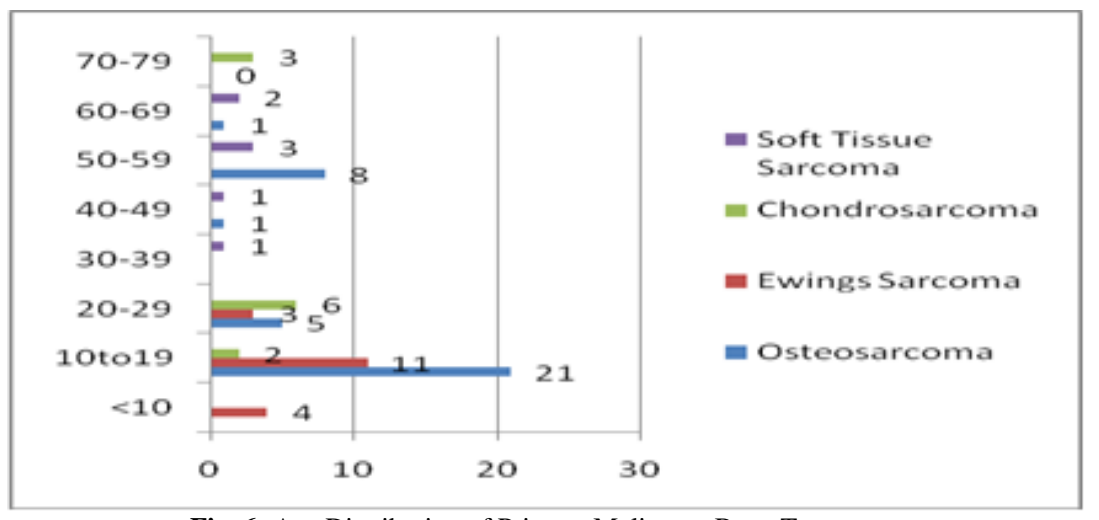

Fig. 6: Age Distribution of Primary Malignant Bone Tumors.

Most of the bone tumors were located around the knee joint i.e. lower end of femur and upper end of the tibia, followed by humerus [Figure 7].

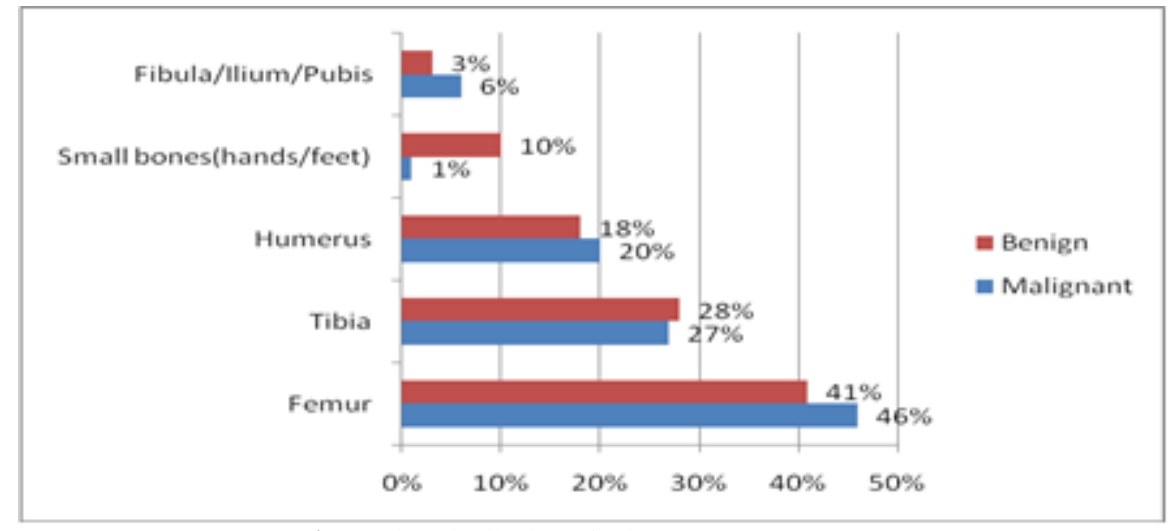

Fig. 7: Site Distribution of Primary Bone Tumors. 


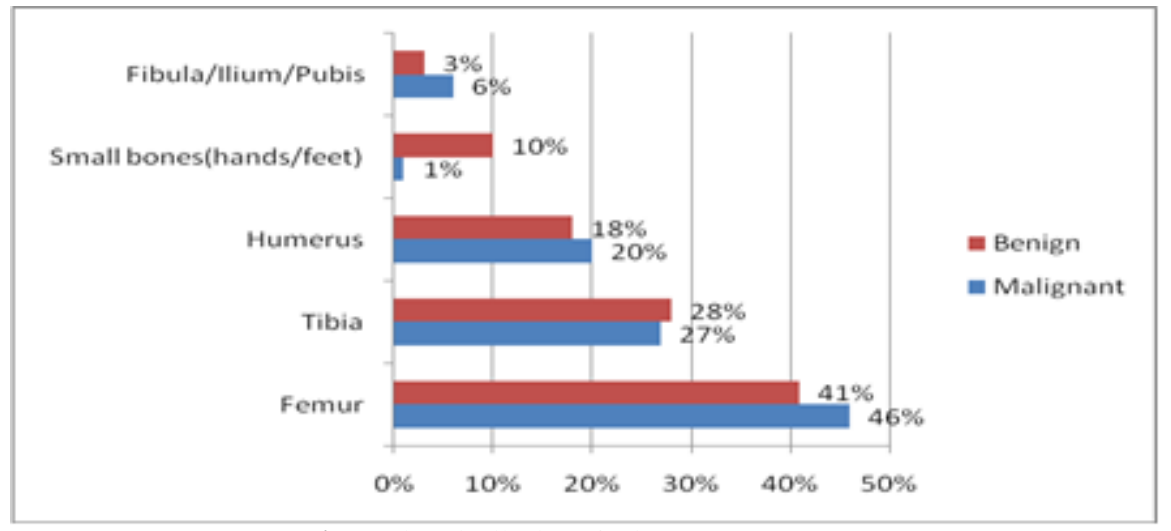

Fig. 7: Site Distribution of Primary Bone Tumors.

\section{Discussion}

There are no reports in the available literature about the pattern of primary bone tumours in Kashmir valley. Reports from other parts of the world show that the primary bone tumors are relatively uncommon lesions constituting less than $1 \%$ of all cancers $[1,2,3]$.

In the present study, we observed that the pattern of bone tumors in Kashmir Valley is very similar to that reported by earlier workers.

In our series, out of 7619 malignancies recorded during the study period, malignant bone tumours numbered only 75 , thus making $0.98 \%$ of all malignancies. Similar low incidence rates of bone cancers were reported in other studies.

O. G. Dodge (1964) reported 44 bone cancers among 2747 malignant lesions recorded in Kenya, thus making $1.6 \%$ of all malignancies. Same author recorded 27 bone cancers $(0.85 \%)$ out of 3172 malignant lesions reported in Uganda.

C. G. H. Price (1977) in his study in South Western England found that the annual incidence of bone cancers was $0.21 \%$ of all malignancies.

Azra Shah (1990) reported 24 bone cancers out of 3310 malignant lesions making $0.72 \%$ of all malignancies recorded from 1983-1987 from another institute in Kashmir.

Thus bone cancers in our study form a small proportion of all malignancies, which corresponds to results from other studies.

Benign bone tumors outnumber malignant ones in the Kashmir valley. In our series, we recorded a total of 373 bone tumours, out of which $298(79.89 \%)$ were benign and $75(20.11 \%)$ were malignant, with benign to malignant ratio being 3.9:1. Similar trends were recorded from other studies. Sarma N. H. et al (1994) recorded a total of 165 bone tumours in a ten year study in Eastern Libya from 1981-1990. In his series, there were 125 benign bone tumours $(57.7 \%)$ against 40 (24.2\%) malignant bone tumours, making a benign to malignant ratio of 3.1: 1.

Similar pattern was recorded by Rao V. S. (1996) in Karnataka over a 36 year study period. In his study, there were a total of 523 bone tumours, out of which 317 (60.6\%) were benign and 206 (39.38\%) were malignant, with a benign to malignant ratio of 1.5:1.

Thus the trend reported by these authors correlates well with that of our study. A slightly higher percentage of benign bone tumours recorded in our study can be explained by the fact that, now, bone lesions are being biopsied more frequently.

Among the malignant tumors, the highest incidence was of Osteosarcoma followed by Ewing's sarcoma and Chondrosarcoma. Osteochondroma was most frequent in the benign category. Males were affected more in comparison to females with $57.64 \%$ males affected against $42.35 \%$ females.

The overall age and sex distribution of bone tumors showed a peak in the second decade with a strong male predominance.

Significantly, femur, tibia and humerus were the most common sites for both benign and malignant bone tumors. The reason for this may be largest growth spurt in these bones during adolescence. Also this reflects the nature of hospital practice as the biopsies were received from orthopedic hospital.

Overall the proportion of primary bone tumors compared to other malignancies in Kashmir valley has been low and malignant bone tumors form a small fraction $(0.98 \%)$ of malignancies [7]. However, trend analysis showed a rising incidence of bone tumors during the last 10 years (Figure 7). This can be attributed to the increase in the number of biopsies received as well as availability of improved and newer diagnostic modalities. We suggest further clinical and epidemiological studies to look into the rising trend of primary bone tumors in this part of the world. 


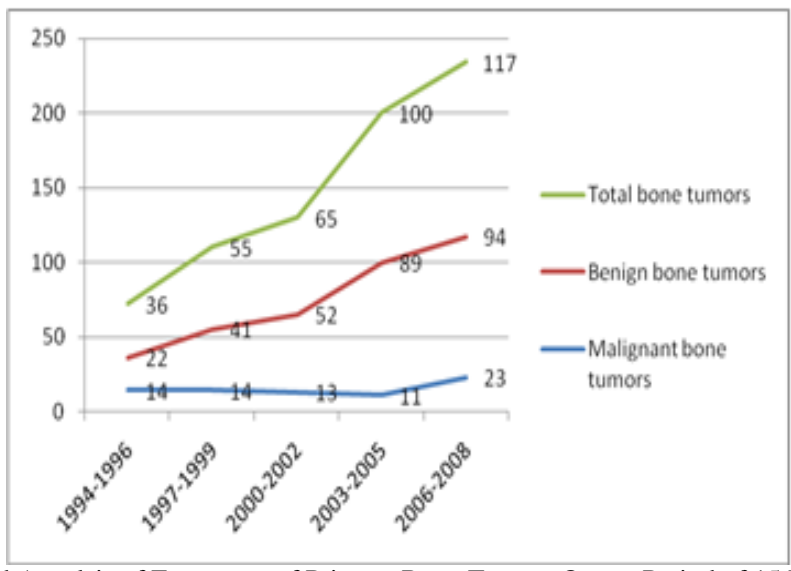

Fig. 7: Trend Anaylsis of Frequency of Primary Bone Tumors Over a Period of 15 Years

\section{Summary and conclusion}

This study shows that the overall frequency of primary bone tumors as compared to other neoplasms in kashmir valley is low. However, there is a rising trend in the incidence of these bone tumours during the last 10 years. Further clinical and epidemiological studies to look into the rising trend of primary bone tumors in this part of the world is warranted.

\section{References}

[1] Yeole B. B, Jussawalla D. J Descriptive epidemiology of bone cancer in greater Bombay.Indian J Cancer. 1998 Sep; 35(3):101-6.

[2] Katchy K. C, Zaid F, Alexander S, Gad H, Abder M. M Malignant bone tumors in Kuwait, a 10 year clinicopathological study. International Orthopaedics 2005; 29: 406-411. http://dx.doi.org/10.1007/s00264-005-0014-6.

[3] Dorfman H. D, Czerniak B Bone cancers.Cancer. 1995 Jan 1; 75(1 Suppl):203-10. http://dx.doi.org/10.1002/10970142(19950101)75:1+<203::AID-CNCR2820751308>3.0.CO;2-V.

[4] Polednak A. P (1985) Primary bone cancer incidence in black and white residents of New York State. Cancer 55: 2883-2888.

[5] Sissons H. A Population studies on bone tumours. Proc R Soc Med. Jun 1971; 64(6): 643-644.

[6] Dodge O. G Bone tumours in Uganda Africans.Br J Cancer 18(4): 627-633, 1964 http://dx.doi.org/10.1038/bjc.1964.72.

[7] Azra S, Jan G. M Pattern of cancer at Srinagar (Kashmir). Indian Jour Pathol Microbiol; 33:2; 118-23, 1990.

[8] Mattoo A. R, Kaul H. K Incidence of malignant neoplasms in Kashmir Jour of Indian Med Ass Vol. 69(9):309-311.1974

[9] Sarma N. H , Al Fituri O, Visweswara R. N, Saeed S. O Primary bone tumour in eastern Libya--a 10 year study.Cent Afr J Med. Jun;40(6):148-51, 1994

[10] Rao V. S, Pai M. R, Rao R. C, Adhikary M. M Incidence of primary bone tumors and tumor like lesions in and around Dakshina Kannada district of Karnataka. J Indian Med Asssoc, 1996 March 94(3); 103-4,121.

[11] Christenson P. C Bone tumors- analysis of one thousand cases with special reference to location, age and sex. Annals of Surgery, 81:1074-92, 1925. http://dx.doi.org/10.1097/00000658-192506010-00004.

[12] Larsson S. E, Lorentzon R The geographic variation of the incidence of malignant primary, bone tumors in Sweden. Journal of Bone and Joint Surgery 56A:592-600, 1974.

[13] Parkin D. M, Stiller C. A, Nectoux J International variations in the incidence of childhood bone tumours. Int J Cancer. 1993 Feb 1; 53(3):3716. http://dx.doi.org/10.1002/ijc.2910530305.

[14] Rosenberg A Robbins pathologic basis of disease 6th edition, 1234, 1999

[15] Uribe-Botero G, Russell W. O, Sutow W. W, Martin R. G Primary osteosarcoma of bone. Clinicopathologic investigation of 243 cases, with necropsy studies in 54. American Journal of Clinical Pathology 1977, 67(5):427-435

[16] Springfield D. S, Capanna R, Gherlinzoni F, Picci P, Campanacci M Chondroblastoma, a review of seventy cases.J Bone Joint Surg Am. 1985 Jun;67(5):748-55.

[17] Fain J. S, Unni K. K, Beabout J. W, Rock MG. Nonepiphyseal giant cell tumor of the long bones. Clinical, radiologic, and pathologic study. Cancer. 1993 Jun 1; 71(11):3514-9. http://dx.doi.org/10.1002/1097-0142(19930601)71:11<3514::AID-CNCR2820711109>3.0.CO;2-A.

[18] Sung H. W, Kuo D. P, Shu W. P, Chai Y. B, Liu C. C, Li S. M Giant-cell tumor of bone: analysis of two hundred and eight cases in Chinese patients. J Bone Joint Surg Am, 1982 Jun; 64(5):755-761.

[19] Dorfman H. D, Czerniak Bogdan Bone tumours 1012-1013 1998. 